\title{
Inquérito sorológico para paramixovirus ofídico em serpentes cativas
}

\section{Serologic survey for ophidian paramyxovirus in captive snakes}

\section{Resumo}

O manejo de serpentes em cativeiro é um desafio permanente para os criadores, principalmente no que tange ao controle de doenças. Parasitoses, problemas gastrointestinais e viroses respiratórias têm sido as principais enfermidades registradas em serpentários e coleções particulares. A maior preocupação é a paramixovirose ofídica, causada pelo Ophidian paramyxovirus (OPMV), que acomete primariamente o sistema respiratório podendo envolver também o nervoso, sendo muitas vezes fatal e que já foi descrita em colubrídeos, elapídeos, viperídeos, boídeos e pitonídeos. O OPMV é transmitido por aerossóis e pelo contato direto com secreções respiratórias, fômites, ectoparasitas tais como os carrapatos e as excretas digestivas. Não há tratamento específico nem vacinas disponíveis para esta virose. Os procedimentos laboratoriais utilizados para o diagnóstico da infecção incluem: isolamento viral em cultivo celular; microscopia eletrônica; imunoistoquímica; reação em cadeia da polimerase (PCR); ou pode-se ainda trabalhar com a quantificação de anticorpos pelo teste de inibição de hemaglutinação $(\mathrm{HI})$ e pelo teste de ELISA (Enzyme Linked Immuno Sorbent Assay) com bloqueio na fase líquida. O presente estudo empregou a técnica de ELISA com bloqueio de fase líquida para investigar a presença de anticorpos anti-OPMV em 42 serpentes, das quais 36 peçonhentas e seis não peçonhentas alojadas no Centro de Estudos de Venenos e Animais Peçonhentos da UNESP - CEVAP. O sangue foi cole- tado da veia caudal ventral e o soro foi enviado ao Laboratório de Virologia do Instituto de Biociências de Botucatu - UNESP. A prevalência de soropositivos foi de 9,5\% (quatro animais), todos pertencentes à espécie Crotalus durissus terrificus. Destes, três apresentavam os maiores títulos de anticorpos (forte positivo) e estavam alojados no serpentário semiextensivo e um, com o menor título (fraco positivo), no intensivo. É sabido que no ambiente semiextensivo, onde os animais estão em contato direto e com a mesma fonte de água, a possibilidade de contágio aumenta. $O$ resultado dos animais fortemente positivos sugere a existência de contato recente com o vírus, porém, sem que os animais expressem sinais de doença. A serpente considerada fraca positiva, alojada no cativeiro intensivo, foi sobrevivente de um surto ocorrido há 12 anos no CEVAP, o que demonstra que os anticorpos podem persistir por anos. Ainda não se sabe se os anticorpos são protetores ou apenas sinalizadores do contágio e se estes animais podem ser considerados como reservatórios da doença. A paramixovirose ofídica é uma doença silenciosa, altamente contagiosa e com muitos casos de morte súbita. Por fim, estudos do tipo caso-controle deverão ser conduzidos para se saber se a presença destes anticorpos indica resistência viral ou reservatório. Neste último caso, a adequada profilaxia da doença incluirá o isolamento dos animais sorologicamente positivos. 


\section{Summary}

The captivity maintenance of snakes is a challenge for the breeders, especially in diseases control. The most common diseases in serpentarium and private collections are the parasites, gastrointestinal problems and respiratory viruses. The biggest concern is the ophidian paramyxovirosis caused by ophidian paramyxovirus (OPMV), which primarily affects the respiratory system and may also involve the nervous system. Often fatal, it was described in Colubridae, Elapidae, Viperidae, Boidae and Pitonidae. This virus is transmitted by aerosols, respiratory secretions, contaminated utensils, ectoparasites such as ticks and digestive excreta. There is no specific treatment or vaccine available. The diagnostic methods are: virus isolation in cell culture; electron microscopy; immunohistochemical; polymerase chain reaction $(P C R)$; hemagglutination-inhibition $(\mathrm{HI})$ and liquid-phase blocking ELISA (Enzyme Linked Immuno Sorbent Assay). This study aimed to make a serological survey, by liquid-phase blocking ELISA, searching to the presence of the anti-OPMV antibodies in 42 snakes (36 poisonous and six, not poisonous) maintained in the Center for the Study of Venoms and Venomous Animals (CEVAP) - UNESP. The serum was collected from caudal ventral vein and sent to the Virology Laboratory of the Biosciences Institute of Botucatu - UNESP for evaluation of antibodies titers. The prevalence of seropositives was $9.5 \%$ (four animals), all of them Crotalus durissus terrificus. Three of these had the highest antibody titers (strong positive) and were maintained in semi-extensive captivity and one with the lowest title (weak positive) was in intensive captive. It is known that in semi-extensive captivity, where the animals are in direct contact with the same source of water, there is higher possibility of infection. The result of the strongly positive animals suggests the possibility of recent virus, but not necessarily expressing signs of illness. The weak positive, kept in intensive captivity, was a survivor of an outbreak 12 years ago in CEVAP, which shows that reptiles remained producing antibodies for years. It is not yet clear if these antibodies are protective or just flags of contagion or if these animals are reservoirs of the disease. The ophidian paramyxovirosis is a silent disease, highly contagious and with many cases of sudden death. Finally, case-control studies should be conducted for the elucidation if these antibodies indicate viral resistance or reservoir conditions. In the last case, the isolation of seropositive animals will be imperative for adequate prophylaxis of the disease.

\section{8}

\section{Palavras-chave}

Serpentes. Paramixovirose ofídica. Infecção. ELISA. Profilaxia.

\section{Keywords}

Snakes. Ophidian paramyxovirus. Infection. ELISA. Prophylaxis.

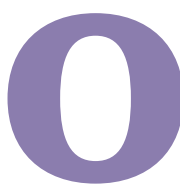

manejo de serpentes em cativeiro é um desafio permanente para os criadores e a eficiência desta criação está diretamente ligada à sobrevida dos animais (COSTA, 2005). $\mathrm{Na}$ atualidade, existem duas principais formas de criação de serpentes: cativeiros intensivos, onde o animal está alojado individualmente, e os semiextensivos onde se alojam grupos em condições similares as existentes na vida livre (MELGAREJO, 2002).

As parasitoses (endo, ecto e hemo) (MADER, 2006), os problemas gastrointestinais (FUNK, 2002) e as viroses respiratórias (JACOBSON, 2014) são as principais enfermidades que tem sido registradas em serpentários e coleções particulares. Dentre elas, a de maior preocupação é a paramixovirose ofídica, causada pelo Ophidian paramyxovirus (OPMV), que apresenta elevada letalidade (JACOBSON, 2014). O OPMV, um vírus envelopado do tipo RNA, acomete primariamente o sistema respiratório dos animais, mas também pode atingir o sistema nervoso. A paramixovirose ofídica já foi descrita em colubrídeos, elapídeos, viperídeos, boídeos e pitonídeos (HYNDMAN; SHILTON; MARSCHANG, 2013). O vírus é facilmente transmitido pelo contato direto, pelas secreções respiratórias, pelos fômites e até por ectoparasitas como os carrapatos (PASMANS

\footnotetext{
1. Discente de graduação de Medicina Veterinária da Universidade Anhembi Morumbi.

2. Professora orientadora Doutora da Clínica de Pequenos Animais da Universidade Anhembi Morumbi.

3. Educadora autônoma Medtronic Brasil em bomba de insulina e CGMS®
} 
et al., 2008). As excretas do trato digestivo também contribuem para a transmissão da virose, especialmente quando as serpentes defecam diretamente no bebedouro de água. Neste caso, o vírus pode continuar viável por longos períodos de tempo (JACOBSON, 2014).

Os sinais clínicos da doença são variáveis, o que dificulta o diagnóstico. Os mais frequentes são: presença de secreção hemorrágica nas narinas e traqueia, dificuldade e estridor respiratório, opistótono, paralisia flácida, tremores de cabeça, alterações de propriocepção, postura corporal anormal, anorexia/regurgitação, diarreia mucoide com odor fétido, letargia e até morte súbita. Na necropsia são observadas alterações principalmente no trato respiratório (JACOBSON et al., 1997; KOLESNIKOVAS et al., 2006; NOGUEIRA et al., 2002; PAPP et al., 2010a; PAPP; SEYBOLD; MARSCHANG, 2010b).

Não há tratamento específico nem vacinas disponíveis no mercado para a profilaxia da paramixovirose ofídica (CRANFIELD; GRACZYK, 1996; JACOBSON et al., 1991; LLOYD; FLANAGAN, 1991). Os antibióticos de amplo espectro têm sido empregados para aumentar a sobrevida dos animais controlando infecções secundárias causadas por bactérias ou protozoários (BRONSON; CRANFIELD, 2006; KOLESNIKOVAS et al., 2006).

Desde a sua primeira descrição em 1972 (FÖLSCH; LELOUP, 1976), o OPMV tornou-se uma preocupação constante para os criadores de serpentes da família Viperidae. Já foram descritos casos de serpentes infectadas pelo OPMV nos EUA, Alemanha, México, Argentina (JACOBSON, 2014) e no Brasil (AZEVEDO et al., 2001; KEEBLE, 2004; KOLESNIKOVAS et al., 2006; NOGUEIRA et al., 2002). Na cidade de Botucatu, estado de São Paulo, Brasil, há indícios da existência de uma endemia de infecção de serpentes pelo OPMV, pois no ano de 2002 foram isoladas amostras deste vírus em um surto no Centro de Estudos de Venenos e Animais Peçonhentos (CEVAP) com uma taxa de mortalidade de mais de 50\% (NOGUEIRA et al., 2002). Funcionários do Centro afirmam (comunicação pessoal) que em 2007 houve um segundo surto em menor proporção, com alguns casos pontuais, onde os animais com sintomatologia respiratória foram eutanasiados. No Brasil, apenas o estado de São Paulo possui relatos da presença deste vírus (AZEVEDO et al., 2001; KOLESNIKOVAS, 2003; KOLESNIKOVAS et al., 2006NOGUEIRA et al., 2002).

$O$ período de incubação das serpentes naturalmente infectadas pelo OPMV é incerto, mas situa-se entre 21 a 90 dias (HERNANDEZ-DIVERS, 2006; RITCHE, 2006). Como todos os paramyxovirus, o problema principal do OPMV é a fase aguda da doença em que ocorre a maioria dos óbitos. Os animais que sobrevivem a fase aguda podem exibir sequelas, apresentam altos títulos de anticorpos e, eventualmente, podem vir a óbito. $\mathrm{O}$ sistema imunológico dos répteis, quando estimulado, trabalha com a imunidade adquirida em longo prazo, aumentando a produção de anticorpos por mais de um ano, visto que estes animais possuem metabolismo basal lento (SANDMEIER et al., 2012). Sabe-se ainda que o OPMV (Paramyxoviridae) está relacionado geneticamente às famílias Filoviridae (vírus do Ebola), Rhabdoviridae (vírus da raiva). As serpentes infectadas pelo OPMV podem se tornar sorologicamente positivas sem que se tenha comprovado a presença do vírus pelo teste do PCR (LEROY et al., 2005; YUAN et al., 2012).

Os métodos laboratoriais aplicados ao diagnóstico da paramixovirose ofídica são: o isolamento viral em cultivo celular (MARSCHANG; CHITTY, 2004); microscopia eletrônica (JACOBSON, 2007); imunoistoquímica (HOMER et al., 1995); PCR (SAND et al., 2004). A quantificação de anticorpos pode ser obtida com a inibição de hemaglutinação (HI) (ALLENDER et al., 2008; QUINN et al., 2002) e o ELISA de bloqueio em fase líquida (ARAÚJO JUNIOR, 1996). O kit diagnóstico comercial mais utilizado se baseia na técnica de inibição de hemaglutinação, porém o seu resultado não é confiável para todas as espécies de serpentes (ALLENDER et al., 2008).

A prevenção da paramixovirose ofídica é realizada pela quarentena dos animais recém-chegados, com período de tempo variando entre 30 dias e seis meses (BRONSON; CRANFIELD, 2006; JACOBSON et al., 1997; KEEBLE, 2004; RITCHE, 2006).

Os inquéritos sorológicos apresentam baixo custo e permitem o exame de um grande número de animais. A vigilância da presença da infecção causada por OPMV em um plantel de ofídeos, utilizando o monitoramento sorológico, permite a realização de programas de controle e prevenção dessa importante enfermidade.

$\mathrm{O}$ presente trabalho realizou um inquérito sorológico com o emprego da técnica de ELISA de bloqueio em fase líquida para avaliar a ocorrência de paramixovirose ofídica nos diversos setores do Centro de Estudos de Venenos e Animais Peçonhentos (CEVAP) da UNESP, campus de Botucatu, SP.

\section{Material e métodos}

Foram examinadas 42 serpentes peçonhentas $(n=36)$ e não peçonhentas $(n=6)$, de nove espécies, alojadas de forma aleatória em quatro ambientes do CEVAP, a saber: quarentenários, museu de visitação, serpentário de manejo intensivo e serpentário de manejo semiextensivo. 
O sangue foi coletado por meio do acesso à veia caudal ventral de um indivíduo Bothrops moojeni, seis Bothrops alternatus, dois Bothrops jararacussu, 27 Crotalus durissus terrificus, dois Python molurus bivittatus, um Boa constrictor amarali, um Eunectes murinus, um Eunectes notaeus e um Hydrodynastes gigas. Os soros foram enviados ao Laboratório de Virologia do Instituto de Biociências de Botucatu - UNESP, para pesquisa de anticorpos anti-OPMV. Todos os animais eram adultos e pesavam no mínimo $1 \mathrm{~kg}$ de peso corpóreo, apresentavam-se hígidos ao exame clínico e não apresentavam sinais clínicos de paramixovirose.

O fluxograma dos animais recém-chegados ao CEVAP inicia-se por uma quarentena de 60 dias. Neste período foram avaliados a biometria, dados de identificação e o estado de saúde geral dos animais. Ao final, os animais peçonhentos da espécie Crotalus durissus terrificus foram direcionados para o cativeiro semiextensivo, em baias coletivas. As demais espécies foram direcionadas ao cativeiro intensivo onde ficam alojadas individualmente em caixas de polipropileno. As serpentes não peçonhentas foram destinadas às baias individuais no museu de visitação.

A pesquisa de anticorpos anti-OPMV por ELISA foi realizada no Laboratório de Virologia do Instituto de Biociências de Botucatu - UNESP. Os antígenos utilizados foram produzidos no Laboratório a partir de um surto de paramixovirose ocorrido no CEVAP em 2002. A padronização da técnica de ELISA foi baseada nos trabalhos prévios de Araújo Junior (1996) e Nogueira et al. (2002). Os resultados da titulação foram apresentados como porcentagem de inibição em relação à amostra controle onde não foram adicionados os soros testes. Animais com porcentagens de inibição maiores que $80 \%$ foram considerados como positivos fortes; de 80 a $40 \%$ como positivos fracos; e menores que $40 \%$ como negativos.

O projeto foi submetido e aprovado pelo Comitê de Ética e Pesquisa da Faculdade de Medicina de Botucatu, UNESP, em 27/09/2012, com número de protocolo CEEA $966 / 2012$.

\section{Resultados}

Os resultados obtidos são apresentados na tabela 1. Quatro serpentes $(9,5 \%)$, todas pertencentes à espécie Crotalus durissus terrificus, apresentaram resultados positivos para OPMV. Destas, três positivos fortes pertenciam ao serpentário semiextensivo e uma, positiva fraca, estava alojada no cativeiro intensivo. Esta última serpente, de acordo com o Banco de dados do CEVAP, é uma das mais antigas do plantel e sobrevivente a um surto de paramixovirose ocorrido em 2002 no CEVAP. Dois animais do cativeiro semiextensivo, positivos fortes, foram a óbito subitamente com sinais clínicos de doença respiratória, com secreção na traqueia, opistótono e incoordenação motora e proprioceptiva. Não houve a possibilidade de coleta de amostra ou exame necroscópico pelo avançado estágio de putrefação que as carcaças apresentavam. Os demais animais apresentavam-se aparentemente saudáveis.

\section{Discussão}

Sabe-se que o OPMV é facilmente transmitido por aerossóis e pelo contato direto com secreções respiratórias, fômites, ectoparasitas como carrapatos, excretas do trato digestivo e por água contaminada (JACOBSON, 2014; PASMANS et al., 2008). No cativeiro semiextensivo onde os animais estavam em contato direto uns com os outros e com a mesma fonte de água, a possibilidade de contágio é maior. Estas observações corroboram os resultados deste estudo, onde três dos quatro animais sorologicamente positivos estavam alojados neste ambiente. As elevadas porcentagens de inibição de anticorpos no teste de ELISA dos animais soropositivos sugerem que os mesmos tinham tido recente contato com o vírus, sem terem expressado os sinais clínicos da doença, assim como ocorreu com o animal sobrevivente do cativeiro semiextensivo. $\mathrm{O}$ animal fraco positivo do cativeiro intensivo era sobrevivente de um surto ocorrido em 2002 no CEVAP, e, portanto, os anticorpos nele detectados podem ter sido remanescentes desta infecção o que é admitido por Sandmeier et al. (2012) que refere a permanência de anticorpos durante muitos anos, no entanto, não pode ser excluída a hipótese de ter ocorrido um novo contato com o vírus.

O cativeiro semiextensivo, apesar de se aproximar das condições existentes na natureza, possui desvantagens para o controle de enfermidades infectocontagiosas, pois os animais mantidos neste ambiente raramente apresentam sinais de doença em seu estágio inicial. No cativeiro intensivo há um maior controle da saúde das serpentes pela presença das barreiras físicas das caixas individualizadas o que reduz ou mesmo evita a transmissão dos patógenos (MELGAREJO, 2002).

A prevenção ainda é a única forma de se efetuar o controle da paramixovirose ofídica, pois não existe um tratamento específico para a enfermidade. A literatura cita períodos de quarentena longos, que vão de 30 dias até seis meses, o que encarece sobremaneira os criatórios (BRONSON; CRANFIELD, 2006; HYNDMAN; SHILTON; MARSCHANG, 2013; JACOBSON et al., 1997; KEEBLE, 2004; RITCHE, 2006) devido ao período de incubação também variável (HERNADEZ-DIVERS, 2006; RITCHE, 2006). Outra possibilidade seria a inclusão de testes sorológicos para pesquisa de OPMV, tais 
como o de ELISA (ARAÚJO JUNIOR, 1996), na rotina de manejo das serpentes em cativeiro. Neste caso, o isolamento destes animais em ambientes especiais seria uma alternativa de manutenção de espécies em extinção.

Não se sabe se as serpentes são reservatórios da doença como acontece nos animais reservatórios do vírus da raiva e do ebola (LEROY et al., 2005; YUAN et al., 2012). A paramixovirose é uma doença silenciosa, altamente contagiosa e com muitos casos de morte súbita (JACOBSON, 2014). As enfermidades causadas por vírus do tipo paramyxo são em sua grande maioria agudas e de curso rápido. Talvez por possuírem metabolismo basal baixo, os répteis de uma maneira geral respondam de forma distinta dos mamíferos (SANDMEIER et al., 2012). Estudos do tipo caso-controle deverão ser conduzidos para se saber até onde a presença de anticorpos anti OPMV indicam condições de resistência viral ou de reservatório natural. Neste último caso, o isolamento dos animais sorologicamente positivos será imperativo para a adequada profilaxia da doença. 0

Tabela 1 - Serpentes alojadas no Centro de Estudos de Venenos e Animais Peçonhentos (CEVAP) da UNESP, campus de Botucatu, SP, submetidas ao teste ELISA com bloqueio de fase líquida para pesquisa de anticorpos anti paramixovirus ofídico segundo o setor de alojamento, a espécie de serpente e a natureza do resultado obtido expresso em densidade óptica (D.O.)

\section{$\begin{array}{lll}\text { LOCAL } & \text { SERPENTE } & \text { PRESENÇA DE ANTICORPOS anti-OPMV }\end{array}$}

Serpentário Intensivo

C. durissus terrificus $(\mathrm{n}=6)$

B. alternatus $(\mathrm{n}=5)$

Título positivo fraco em 1

C. durissus terrificus ( $D . O=47 \%$ )

B. jararacussu $(\mathrm{n}=1)$

Serpentário Semiextensivo

C. durissus terrificus $(\mathrm{n}=15)$

Títulos fortemente positivos em 3

C. durissus terrificus (D.O. $=10 \%, 10 \%$ e $6 \%$ )

Quarentenários

C. durissus terrificus $(\mathrm{n}=4)$

B. moojeni $(\mathrm{n}=1)$

Titulos negativos (D.O > 60\%)

Museu de visitação
Títulos negativos (D.O > 60\%)

E. murinus $(\mathrm{n}=1)$

B. alternatus $(\mathrm{n}=1)$

B. jararacussu $(\mathrm{n}=1)$ 


\section{Referências}

ALLENDER, M. C. et al. Measuring agreement and discord among hemagglutination inhibition assays against different ophidian paramyxovirus strains in Eastern massasauga (Sistrurus catenus catenus). J. Zoo Wildl. Med., Yulee, v. 39, n. 3, p. 358-361, Sept 2008.

ARAÚJO JUNIOR, J. P. ELISA de bloqueio em fase líquida com diluição única para quantificação de anticorpos contra o paramyxovírus ofídico em soros de serpentes. 1996. 28 f. Tese (Livre Docência) - Universidade Estadual Paulista, Botucatu, 1996.

AZEVEDO, I. L. J. et al. Characterization of a paramyxovirus from Fer de Lance viper: partial nucleotide sequence of putative fusion protein. Arch. Virol., Wien, v. 146, n. 1 p. 51-57, 2001.

BRONSON, E.; CRANFIELD, M. R. Paramyxovirus. In: MADER, D. R. (Ed.). Reptile medicine and surgery. St. Louis: Elsevier, 2006. p. 858-861.

COSTA, A. C. O. R. et al. Manutenção de serpentes em cativeiro no Instituto Butantan: I- a longevidade dos gêneros Bothrops, Crotalus e Lachesis. Publs. Av. Inst. Pau Brasil n. 8-9, p. 63-8, dez. 2005

CRANFIELD, M. R.; GRACZYK, T. K. Ophidian Paramyxovirus. In: MADER, D. (Ed.). Reptile medicine and surgery. Philadelphia: WB Saunders, 1996. cap. 63, p. 858861.

FÖLSCH, D. W.; LELOUP, P. Fatal endemic infection in a serpentarium. Diagnosis, treatment and preventive measures. Tierarztl. Prax., Stuttgart, v. 4, n. 4, p. 527-536 1976.

FUNK, R. S. Lizard reproductive medicine and surgery. Vet. Clin. North Am. Exot. Anim. Pract., Philadelphia, v. 5, n. 3, p. 579-613, Sept. 2002.

HERNANDEZ-DIVERS, S. J. Appendix A - reptile viral diseases - summary table. In MADER, D. R. (Ed.). Reptile medicine and surgery. St. Louis: Elsevier, 2006. p. 1147 1158.

HOMER, B.L. et al. Immunoperoxidase detection of ophidian paramyxovirus in snake lung using a polyclonal antibody. J. Vet. Diagn. Invest., Columbia, MO, v. 7, n. 1, p 72-77, Jan. 1995

HYNDMAN, T. H.; SHILTON, C. M.; MARSCHANG, R. E. Paramyxoviruses in reptiles: a review. Vet. Microbiol., Amsterdam, v. 165, n. 3-4, p. 200-213, Aug. 2013.

JACOBSON, E. R. Ophidian Paramyxovirus (OPMV). [Florida: University Florida] 2014. Disponível em: <http://labs.vetmed.ufl.edu/sample-requirements/microbiologyparasitology-serology/zoo-med-infections/opm/>. Acesso em: 16 fev. 2015.

JACOBSON, E. R. Viruses and viral diseases of reptiles. In: JACOBSON, E. R. Infectious diseases and pathology of reptiles: color atlas and text. Florida: Taylor \& Francis, 2007. p. 395-460.

JACOBSON, E. R. et al. Antibody responses of Western Diamondback rattlesnakes (Crotalus atrox) to inactivated ophidian paramyxovirus vaccines. J. Zoo Wildl. Med. Yulee, v. 22, n. 2, p. 184-190, June 1991

JACOBSON, E. R. et al. Pulmonary lesions in experimental ophidian paramyxovirus pneumonia of Aruba Island Rattlesnakes, Crotalus unicolor. Vet. Pathol., Basel, v. 34, n. 5, p. 450-459, Sept. 1997.

KEEBLE, E. Neurology. In: GIRLING, S.; RAITI, P. BSAVA manual of reptiles. Gloucester: British Small Animal Veterinary Association, 2004. p. 273-288.
KOLESNIKOVAS, C. K. M. Infecção experimental por Paramyxovirus em serpentes Boa constrictor (LINNAEUS, 1758). Estudo anátomo-patológico, imunoistoquímico, microbiológico, hematológico e sorológico. 2003. 115 f. Tese (Doutorado) - Faculdade de Medicina Veterinária e Zootecnia, Universidade de São Paulo, 2003. Disponível em: <http://www.teses.usp.br/teses/disponiveis/10/10133/ tde-21062007-140639/>. Acesso em: 5 jan. 2015.

KOLESNIKOVAS, C. K. et al. Ophidian paramyxovirus in Brazilian vipers (Bothrops alternatus). Vet. Rec., London, v. 159, n. 12, p. 390- 392, Sept. 2006.

LEROY, E. M. et al. Fruit bats as reservoirs of Ebola virus. Nature, London, v. 438, n. 7068, p. 575-576, Dec. 2005

LLOYD, M. L.; FLANAGAN, J. Recent developments in ophidian paramyxovirus research and recommendations on control. In: PROCEEDINGS of the American Association of Zoo Veterinarians. 1991. Philadelphia: American Association of Zoo Veterinarians, 1991. p. 148-153.

MADER, D. R. Parasitology. In: MADER, D. R. (Ed.). Reptile medicine and surgery St. Louis: Elsevier, 2006. p. 343-364.

MARSCHANG, R. E.; CHITTY, J. Infectious diseases. In: BSAVA manual os reptiles. Gloucester: British Small Animal Veterinary Association, 2004. p. 330-345.

MELGAREJO, A. R. Criação e manejo de serpentes. In: ANDRADE, A.; PINTO, S. C.; OLIVEIRA, R. S. (Org.). Animais de laboratório: criação e experimentação. Rio de Janeiro: Editora FIOCRUZ, 2002. p. 175-199.

NOGUEIRA, M. F. et al. Isolation of an Ophidian Paramyxovirus (OPMV) in a captive rattlesnake (Crotalus durissus terrificus) from Botucatu, São Paulo State, Brazil. J. Venom. Anim. Toxins, Botucatu, v. 8, n. 1, p. 168-173, 2002.

PAPP, T. et al. RT-PCR diagnosis followed by sequence characterization of paramyxoviruses in clinical samples from snakes reveals concurrent infections within populations and/or individuals. Vet. Microb., Amsterdam, v. 144, n. 3-4, p. 466472, Aug. 2010a.

PAPP, T.; SEYBOLD, S.; MARSCHANG, R. E. Paramyxovirus infection in a Leopard Tortoise (Geochelone pardalis babcocki) with respiratory disease. J. Herpetol. Med. Surg., Lawrence, KS, v. 20, n. 2-3, p. 64-68, June-Sept. 2010b.

PASMANS, F. et al. Introducing reptiles into a captive collection: the role of the veterinarian. Vet. J., London, v. 175, n. 1, p 53-68, Jan. 2008

QUINN, P. J. et al. Paramyxoviridae. In: QUINN, P. J.; MARKEY B. K.; CARTER, M. E.; DONNELLY, W. J.; LEONARD, F. C. Veterinary microbiology and microbial disease. Oxford: Blackwell Science, 2002. p. 381-389.

RITCHE, B. Virology. In: MADER, D. R. (Ed.). Reptile medicine and surgery. St Louis: Elsevier, 2006. p. 391-417.

SAND, M. A. et al. Molecular diagnosis of paramyxovirus infection in snakes using reverse transcriptase-polymerase chain reaction and complementary deoxyribonucleic acid in situ hybridization. J. Vet. Diagn. Invest., Columbia, MO, v. 16, n. 5, p. 442448 , Sept. 2004

SANDMEIER, F. C. et al. A trade-off between natural and acquired antibody production in a reptile: implications for long-term resistance to disease. Biol. Open, Cambridge, v. 1, n. 11, p. 1078-1082, Nov. 2012.

YUAN, J. et al. Serological evidence of ebolavirus infection in bats, China. Virol. J. [London], v. 9, p. 236, Oct. 2012. 